\title{
The effects of circuit training on the indexes of sarcopenia and the risk factors of metabolic syndrome in aged obese women
}

\author{
Hyang-Beum Lee, Han-Kyung Lee* \\ Department of Physical Education, Yong In University, Yongin, Korea
}

The purpose of this study is to examine the effects of circuit training on the indexes of sarcopenia and the risk factors of metabolic syndrome in aged obese women. To address the goal, this author selected aged women whose body mass index was higher than $25.0 \mathrm{~kg} / \mathrm{m}^{2}$ visiting the welfare center for the aged located in Gangwon-do Province and measured the indexes of sarcopenia and the risk factors of metabolic syndrome after circuit training. Through that, this study has gained following results. First, after circuit training, aged obese women's indexes of sarcopenia indicated statistically significant difference in terms of interaction between the measuring times and groups. Second, after circuit training, aged obese women's risk factors of metabolic syndrome (systolic blood pressure, diastolic blood pressure, fasting blood sugar, triglycerides, high- density lipoprotein-cholesterol, and waist circumference) showed statistically significant difference in terms of interaction between the measuring times and groups. To sum up the above results, circuit training improves aged obese women's indexes of sarcopenia and risk factors of metabolic syndrome positively, which means circuit training is found to be effective. Therefore, the circuit training intervention enhances aged obese women's muscular and metabolic functions positively. As it helps prevent and manage the risk factors of sarcopenia and metabolic syndrome resulted from aging, it will elevate life quality in senescence.

Keywords: Circuit training, Sarcopenia, Metabolic syndrome, Aged women, Obesity

\section{INTRODUCTION}

As we grow older, we get to face reduction in physical function, increase in body fat, and also decrease in muscle mass, which lowers our life quality in senescence overall. The aged have possibility of getting various types of degenerative diseases, and they may get even worse time after time, which leads to increase in their medical expenses. Due to these social problems, health issues in senescence are now rising as one of the most serious tasks that contemporary society should solve (Morley et al., 2014). The biggest concern related to health in senescence has been obesity; however, lately, sarcopenia is regarded as a more serious health problem (Siparsky et al., 2014).

Sarcopenia is a condition that appears in the aged whose muscle mass and muscular functions are reducing (Rosenberg, 1997). In

2016, the Unite States registered it officially as a disease. Muscle mass reduces gradually from 40 and is rapidly lost after 60 . About $2 \%$ of muscle mass is lost each year (Rom et al., 2012). It is reported that muscular strength reduces as 3\% every year (Goodpaster et al., 2006). These phenomena of muscular strength and muscle mass reducing with aging are something natural, and the bigger cause of them is not aging itself but reduction in physical activity. If you move your body less, myoatrophy is accelerated. This reduces muscle mass and lowers basal metabolism eventually. With this change, surplus energy increases, and it leads to the accumulation of lipids. This is the cause of many health problems, for instance, negative reinforcement for blood pressure or blood glucose (Arnett et al., 2008).

According to the annual report of health examination statistics released by National Health Insurance Corporation, 24\% of those

${ }^{*}$ Corresponding author: Han-Kyung Lee (D) https://orcid.org/0000-0002-9019-6291 Department of Physical Education, Yong In University, 134 Yongindaehak-ro, Cheoin-gu, Yongin 17092, Korea

Tel: +82-31-8020-2676, Fax: +82-31-8020-2883, E-mail: hglee2676@hanmail.net Received: April 27, 2018 / Accepted: June 12, 2018 
who have received a health examination are classified to have metabolic syndrome in which metabolic risk factors for cardiovascular disease are concentrated. These phenomena got deeper with aging, and after the 60's, woman are classified to have metabolic syndrome more than men; therefore, it is important for aged women to manage metabolic syndrome properly (National Health Insurance Service, 2015). Metabolic syndrome refers to the condition that metabolic risk factors for cardiovascular disease are concentrated. When three out of blood pressure, fasting blood sugar (FBS), triglycerides (TG), high-density lipoprotein (HDL)-cholesterol, and the waist circumference (WC) correspond to the criteria, it is defined as metabolic syndrome (Festa et al., 2000).

There are many ways to manage metabolic syndrome, and as a nonpharmacological method, exercise therapy is being stressed. As exercise therapy can be used to enhance muscle functions and cardiopulmonary functions, it is being highlighted as an effective health management method for the aged. But generally, weight training raises the risk of injuries and takes monotonous patterns, so it is rather difficult to keep practicing it with interest. Among a lot of training methods, circuit training lasts rather shortly compared to other types of training and involves various sport events. Participants may do the exercise continuously with interest and can develop a variety of elements of physical strength within a short time (Davis et al., 2000), so this researcher expects that it can be used as an effective training method for aged women.

Since the circuit training intervention allows you to experience various sport events within a short time, you may keep practicing it with interest. If it is found to influence the indexes of sarcopenia and the risk factors of metabolic syndrome in aged obese women positively, it will be more applicable to the field to improve health in senescence. Here, this study will examine the effects of circuit training on the indexes of sarcopenia and the risk factors of metabolic syndrome with aged obese women whose body mass index (BMI) is higher than $25.0 \mathrm{~kg} / \mathrm{m}^{2}$ and provide foundational material that can be used for the aged to manage their health effectively and improve their life quality.

\section{MATERIALS AND METHODS}

\section{Study subjects}

The subjects of this study are old obese women aged 65 or older who are visiting the welfare center for the aged located in Gangwon-do Province and whose BMI is over $25.0 \mathrm{~kg} / \mathrm{m}^{2}$. When selecting the subjects, this author excluded those participating in any physical activity program as it could influence the result. To
Table 1. The physical characteristics of subjects

\begin{tabular}{lcc}
\hline Variable & Exercise group $(\mathrm{n}=12)$ & Control group $(\mathrm{n}=12)$ \\
\hline Age $(\mathrm{yr})$ & $71.13 \pm 2.75$ & $72.13 \pm 2.72$ \\
Height $(\mathrm{cm})$ & $155.42 \pm 3.13$ & $154.83 \pm 2.77$ \\
Weight $(\mathrm{kg})$ & $64.39 \pm 1.85$ & $64.89 \pm 2.50$ \\
Body mass index $\left(\mathrm{kg} / \mathrm{m}^{2}\right)$ & $26.68 \pm 1.21$ & $27.08 \pm 1.09$ \\
\hline
\end{tabular}

Values are presented as mean \pm standard deviation.

prevent the diffusion effect of this experimental intervention, this researcher chose the experimental group and control group from two different places far from each other. Before providing the circuit training intervention for aged obese women, this author explained the purpose of this study and received a written agreement from them. As it might influence the result between experiments, the intake of drugs or nutritional supplements was limited. The individual characteristics of the subjects are shown in Table 1.

\section{Measured items and measuring methods}

This study has examined how the indexes of sarcopenia and the risk factors of metabolic syndrome change in aged obese women according to 8-week circuit training.

As the indexes of sarcopenia, this researcher used skeletal muscle indexes (SMIs) suggested by Janssen et al. (2002). Regarding the muscle indexes, bio impedance analyzer was employed to measure weight and skeletal muscle mass, and they were substituted to a muscle index formula to calculate the indexes of sarcopenia; SMI $=$ (skeletal muscle mass $/$ weight $) \times 100$.

The risk factors of metabolic syndrome were measured by systolic blood pressure (SBP), diastolic blood pressure (DBP), FBS, TG, HDL-cholesterol, and WC. SBP and DBP were measured twice with an electronic blood pressure gauge, and smaller values were recorded. FBS, TG, and HDL-Cholesterol were measured through a blood test. About the blood test, the disposable syringe was used to get the blood sample of $12 \mathrm{~mL}$ from the forearm vein, and it was sent to Samkwang Medical Laboratories for analysis. Lastly, WC was measured and then recorded from the subjects while standing at the region between the lowermost part of the ribs and ilia.

\section{The circuit training program}

The circuit training program used in this study was designed by referring to the elements of frequency, intensity, time, type suggested by American College of Sports Medicine (2014) recommendation guidelines for exercise. As the guidelines say that exercise should last for 8 to 12 weeks, 30 to $40 \mathrm{~min}$ in each session, 3 
to 5 times a week, to see the effects from the aged, this author provided the circuit training program 3 times a week, 50 min each time, for 8 weeks.

As warm-up and warm-down, they were asked to do stretching and walk on a tread mill for $10 \mathrm{~min}$. This exercise program is designed as a program that can stimulate gross motor skills with dumbbells and with no tools after a meeting with three experts having a doctoral degree in physical education. This exercise includes dumbbell press, dumbbell curl, dumbbell triceps extension, push up, crunch, back extension, squat, and standing calf raise, and each lasted for $40 \mathrm{sec}, 12$ to 15 times, as 3 sets repeated. The resting time between events lasted for $20 \mathrm{sec}$, and the resting time between sets was controlled as $2 \mathrm{~min}$. The intensity of this exercise was set as RPE 11 to 14 with the application of Borg Scale.

\section{Data processing}

This study adopts pretest-posttest control group design and uses IBM SPSS Statistics ver. 22.0 (IBM Co., Armonk, NY, USA), to analyze the effects of circuit training on aged obese women. To examine the subjects' physical characteristics, descriptive statistical analysis was performed to calculate the mean and standard deviation. To investigate how the indexes of sarcopenia and the risk factors of metabolic syndrome change in aged obese women according to circuit training, repeated measure analysis of variance was conducted. The statistically significant level about the results was set as 0.05 for verification. Because the significant level of the results is influenced by the number of samples, Partial $\eta^{2}$ was calculated to present the intensity of correlation.

\section{RESULTS}

\section{The indexes of sarcopenia changed according to circuit training}

According to the results of the homogeneity test on variate and covariate matrixes regarding the indexes of sarcopenia changed according to aged obese women's participation in circuit training, Box $M=2.627, F(3,141,120.000)=0.808$, and $P=0.489$; there-

Table 2. The indexes of sarcopenia changed according to circuit training

\begin{tabular}{lcclrrc}
\hline Group & Pretest & Posttest & & $F$ & $P$-value & $\eta p^{2}$ \\
\hline EG & $33.97 \pm 1.47$ & $34.95 \pm 1.47$ & Group & 4.293 & 0.048 & 0.133 \\
CG & $33.35 \pm 1.80$ & $33.09 \pm 1.83$ & Time & 37.958 & 0.001 & 0.575 \\
& & & GxT & 109.345 & 0.001 & 0.796 \\
\hline
\end{tabular}

Values are presented as mean \pm standard deviation.

EG, exercise group; $C G$, control group. fore, the equivalence hypothesis is found to be supported. According to the results of verifying Mauchly sphericity hypothesis, Huynh-Feldt $\varepsilon$ is found to be 1 ; therefore, the hypothesis is also supported.

How the indexes of sarcopenia change according to aged obese women's participation in circuit training is shown in Table 2. As shown in Table 2, the indexes of sarcopenia changed according to aged obese women's participation in circuit training are found to have interactive effects.

\section{The risk factors of metabolic syndrome changed according to circuit training}

According to the results of the homogeneity test on variate and covariate matrixes regarding the risk factors of metabolic syndrome changed according to aged obese women's participation in circuit training, $\mathrm{SBP}$ is found to show Box $M=5.699, F(3,141,120.000)=$

Table 3. The risk factors of metabolic syndrome changed according to circuit training

\begin{tabular}{|c|c|c|c|c|c|c|}
\hline Group & Pretest & Posttest & & $F$ & $P$-value & $\eta p^{2}$ \\
\hline \multicolumn{7}{|l|}{ SBP } \\
\hline EG & $122.33 \pm 8.91$ & $108.20 \pm 6.81$ & Group & 4.282 & 0.048 & 0.133 \\
\hline \multirow[t]{2}{*}{$\mathrm{CG}$} & $120.07 \pm 8.91$ & $122.27 \pm 7.75$ & Time & 134.626 & 0.001 & 0.828 \\
\hline & & & $\mathrm{G} \times \mathrm{T}$ & 252.206 & 0.001 & 0.900 \\
\hline \multicolumn{7}{|l|}{ DBP } \\
\hline EG & $84.27 \pm 3.90$ & $78.47 \pm 3.76$ & Group & 4.199 & 0.050 & 0.130 \\
\hline \multirow[t]{2}{*}{ CG } & $84.53 \pm 5.80$ & $85.13 \pm 5.44$ & Time & 30.204 & 0.001 & 0.519 \\
\hline & & & $\mathrm{G} \times \mathrm{T}$ & 45.753 & 0.001 & 0.620 \\
\hline \multicolumn{7}{|l|}{ FBS } \\
\hline EG & $93.87 \pm 7.15$ & $86.00 \pm 7.00$ & Group & 1.411 & 0.245 & 0.048 \\
\hline \multirow[t]{2}{*}{ CG } & $92.47 \pm 5.01$ & $92.67 \pm 4.94$ & Time & 205.266 & 0.001 & 0.880 \\
\hline & & & $\mathrm{G} \times \mathrm{T}$ & 227.244 & 0.001 & 0.890 \\
\hline \multicolumn{7}{|l|}{ TG } \\
\hline EG & $147.27 \pm 10.56$ & $139.87 \pm 10.56$ & Group & 0.047 & 0.831 & 0.002 \\
\hline \multirow[t]{2}{*}{ CG } & $142.73 \pm 7.92$ & $142.93 \pm 8.25$ & Time & 40.024 & 0.001 & 0.588 \\
\hline & & & $G \times T$ & 44.594 & 0.001 & 0.614 \\
\hline \multicolumn{7}{|l|}{ HDL-C } \\
\hline EG & $49.93 \pm 2.449$ & $53.07 \pm 2.81$ & Group & 4.470 & 0.044 & 0.138 \\
\hline \multirow[t]{2}{*}{ CG } & $49.67 \pm 3.24$ & $48.93 \pm 3.17$ & Time & 19.302 & 0.001 & 0.408 \\
\hline & & & $\mathrm{G} \times \mathrm{T}$ & 50.102 & 0.001 & 0.641 \\
\hline \multicolumn{7}{|l|}{ WC } \\
\hline EG & $84.63 \pm 2.84$ & $81.74 \pm 2.63$ & Group & 4.341 & 0.046 & 0.134 \\
\hline \multirow[t]{2}{*}{ CG } & $85.05 \pm 3.17$ & $85.81 \pm 3.23$ & Time & 72.317 & 0.001 & 0.721 \\
\hline & & & $G \times T$ & 212.636 & 0.001 & 0.884 \\
\hline
\end{tabular}

Values are presented as mean \pm standard deviation.

SBP, systolic blood pressure; DBP, diastolic blood pressure; FBS, fasting blood sugar; TG, triglycerides; HDL-C, high-density lipoprotein-cholesterol; WC, waist circumference; $\mathrm{EG}$, exercise group; $\mathrm{CG}$, control group. 
1.753 , and $P=0.154$, and DBP indicates Box $M=2.362, F$ ( 3 , $141,120.000)=0.727$, and $P=0.536$, and FBS shows Box $M=$ 5.569, $F(3,141,120.000)=1.713$, and $P=0.162$, and TG is found to indicate Box $M=1.562, F(3,141,120.000)=0.480$, and $P=0.696$, and HDL-Cholesterol shows Box $M=1.700, F(3,141,120.000)=$ 0.523 , and $P=0.667$, and lastly, WC indicates Box $M=1.929, F$ $(3,141,120.000)=0.593$, and $P=0.619$; therefore, the equivalence hypothesis is found to be supported. According to the results of verifying Mauchly's sphericity hypothesis, all the variables indicate 1 as Huynh-Feldt $\varepsilon$; therefore, the hypothesis is supported, too.

How the risk factors of metabolic syndrome change according to aged obese women's participation in circuit training is shown in Table 3. As shown in Table 3, aged obese women's risk factors of metabolic syndrome, SBP, DBP, FBS, TG, HDL-cholesterol, and $\mathrm{WC}$, are found to have interactive effects according to their participation in circuit training.

\section{DISCUSSION}

This study has examined the effects of circuit training on the indexes of sarcopenia and the risk factors of metabolic syndrome in aged obese women. In order to suggest a scientific exercise program for aged obese women's better health management and life quality, this author investigated and analyzed the effects of an 8 -week circuit training intervention through comparison with advanced studies.

Sarcopenia is a condition of muscle mass and muscular strength reduced with aging (Rosenberg, 1997). As it involves high riskiness for many metabolic diseases, in 2016, the United States gave it a disease code (ICD10-CM, M62.84) officially and registered it as a disease (Anker et al., 2016). Sarcopenia appearing in the aged reduces their ability for fat oxidation and increases their body fat. As a result of this, various metabolic diseases and chronic diseases may attack them with the mediation of obesity (Mitchell et al., 2012). In this sense, in order to increase aged obese women's muscle mass and muscular strength, this author provided a circuit training intervention for aged obese women and observed how the indexes of sarcopenia changed.

According to the results of verifying the effects of circuit training on the indexes of sarcopenia in aged obese women, statistically significant difference is found in interactive effects between the measuring times and groups. This implies that circuit training increases muscle mass and muscular strength effectively in aged obese women and improves the indexes of sarcopenia positively. The result of this study corresponds to the result of von Stengel et al. (2012) that has asked aged women to perform a complex exercise with the intensity of maximal heart rate $70 \%-80 \%$ for 18 months and found their sarcopenia has been improved with the significant reduction of their body fat percentage and increase of their fat-free mass, to the result of Cadore et al. (2014) that a complex exercise is helpful in improving sarcopenia with no change in their weight but with the reduction of their body fat and increase of their fat-free mass, and also to the result of Halverstadt et al. (2007) that has asked the aged to participate in a regular exercise three times a week for 24 weeks and found that their fat-free mass has increased significantly. All of these support the result of this study. This author think this result is gained because the circuit training intervention provided to aged obese women whose physical activity is rather reduced stimulates their global muscle groups and has them synthesize more protein, thereby improving their muscle mass and muscular strength. The result of this study seems meaningful as it presents the possibility of applying the circuit training intervention as a way of improving aged obese women's sarcopenia because it can prevent and manage muscle loss in senescence resulted from the changes of hormones as well as reduction of physical activity.

The changes of hormones and reduction of physical activity resulted from aging often lead to obesity, chronic disease, musculoskeletal disorder, or problems in the immune system (Butte et al., 2007). This also causes a vicious cycle leading to even more reduced physical activity with damaged physical and mental functions limiting them to lead an independent life. In this sense, it is needed to prevent and improve the damage of physical and mental functions resulted from the changes of hormones as well as reduction of physical activity. To obtain independency and heighten life quality in senescence, this author provided the circuit training intervention and observed how the risk factors of metabolic syndrome changed.

According to the results of verifying the effects of circuit training on the risk factors of metabolic syndrome in aged obese women, the risk factors of metabolic syndrome, SBP, DBP, FBS, TG, HDL-Cholesterol, and WC, are found to indicate statistically significant difference in terms of interactive effects between the measuring times and groups. This implies that the circuit training intervention improves aged obese women's blood circulation through exercise and metabolic functions through fat oxidation, thereby reducing the risk factors of metabolic syndrome. The result of this study corresponds to the result of Tjønna et al. (2008) that has asked patients with metabolic syndrome to participate in interval training for 16 weeks and found that the number of risk 
factors for metabolic syndrome has decreased significantly, to the result of Stensvold et al. (2010) that 12-week circuit training is effective in improving the risk factors of metabolic syndrome, and to the result of Villareal et al. (2006) that has asked extremely obese males and females to conduct an exercise for 26 weeks and found their metabolic syndrome has been improved significantly. All of these support the result of this study. This author thinks that the result of this study is gained because the circuit training intervention betters the condition of body lipids by oxidizing surplus energy increased by the reduction of physical activity and enhances physical functions by making muscles get bigger. Therefore, to prevent obesity and the risk factors of metabolic syndrome caused by aging and lessened physical activity and lead a healthy life in senescence, it is possible to apply circuit training consisting of many different events. As it allows participants to do exercise with no boredom and participate in it voluntarily with interest, it can turn out to be an effective method to practice health management properly and enhance life quality in senescence.

\section{CONFLICT OF INTEREST}

No potential conflict of interest relevant to this article was reported.

\section{REFERENCES}

American College of Sports Medicine. ACSM's guidelines for exercise testing and prescription. 9nd ed. Philadelphia (PA): Lippincott Williams \& Wilkins; 2014.

Anker SD, Morley JE, von Haehling S. Welcome to the ICD-10 code for sarcopenia. J Cachexia Sarcopenia Muscle 2016;7:512-514.

Arnett SW, Laity JH, Agrawal SK, Cress ME. Aerobic reserve and physical functional performance in older adults. Age Ageing 2008;37:384389.

Butte NF, Puyau MR, Adolph AL, Vohra FA, Zakeri I. Physical activity in nonoverweight and overweight Hispanic children and adolescents. Med Sci Sports Exerc 2007;39:1257-1266.

Cadore EL, Pinto RS, Bottaro M, Izquierdo M. Strength and endurance training prescription in healthy and frail elderly. Aging Dis 2014;5:183195.

Davis JM, Alderson NL, Welsh RS. Serotonin and central nervous system fatigue: nutritional considerations. Am J Clin Nutr 2000;72(2 Suppl): 573S-578S.

Festa A, D'Agostino R Jr, Howard G, Mykkänen L, Tracy RP, Haffner $\mathrm{SM}$. Chronic subclinical inflammation as part of the insulin resistance syndrome: the Insulin Resistance Atherosclerosis Study (IRAS). Circulation 2000;102:42-47.

Goodpaster BH, Park SW, Harris TB, Kritchevsky SB, Nevitt M, Schwartz AV, Simonsick EM, Tylavsky FA, Visser M, Newman AB. The loss of skeletal muscle strength, mass, and quality in older adults: the health, aging and body composition study. J Gerontol A Biol Sci Med Sci 2006; 61:1059-1064.

Halverstadt A, Phares DA, Wilund KR, Goldberg AP, Hagberg JM. Endurance exercise training raises high-density lipoprotein cholesterol and lowers small low-density lipoprotein and very low-density lipoprotein independent of body fat phenotypes in older men and women. Metabolism 2007;56:444-450.

Janssen I, Heymsfield SB, Ross R. Low relative skeletal muscle mass (sarcopenia) in older persons is associated with functional impairment and physical disability. J Am Geriatr Soc 2002;50:889-896.

Mitchell WK, Williams J, Atherton P, Larvin M, Lund J, Narici M. Sarcopenia, dynapenia, and the impact of advancing age on human skeletal muscle size and strength; a quantitative review. Front Physiol 2012;3: 260.

Morley JE, von Haehling S, Anker SD, Vellas B. From sarcopenia to frailty: a road less traveled. J Cachexia Sarcopenia Muscle 2014;5:5-8.

National Health Insurance Service. Statistical Yearbook. Wonju (Korea): National Health Insurance Service; 2015.

Rom O, Kaisari S, Aizenbud D, Reznick AZ. Lifestyle and sarcopenia-etiology, prevention, and treatment. Rambam Maimonides Med J 2012;3: $\mathrm{e} 0024$.

Rosenberg IH. Sarcopenia: origins and clinical relevance. J Nutr 1997;127 (5 Suppl):990S-991S

Siparsky PN, Kirkendall DT, Garrett WE Jr. Muscle changes in aging: understanding sarcopenia. Sports Health 2014;6:36-40.

Stensvold D, Tjønna AE, Skaug EA, Aspenes S, Stølen T, Wisløff U, Slørdahl SA. Strength training versus aerobic interval training to modify risk factors of metabolic syndrome. J Appl Physiol (1985) 2010;108:804-810.

Tjønna AE, Lee SJ, Rognmo Ø, Stølen TO, Bye A, Haram PM, Loennechen JP, Al-Share QY, Skogvoll E, Slørdahl SA, Kemi OJ, Najjar SM, Wisløff $\mathrm{U}$. Aerobic interval training versus continuous moderate exercise as a treatment for the metabolic syndrome: a pilot study. Circulation 2008; 118:346-354.

Villareal DT, Miller BV 3rd, Banks M, Fontana L, Sinacore DR, Klein S. Effect of lifestyle intervention on metabolic coronary heart disease risk factors in obese older adults. Am J Clin Nutr 2006;84:1317-1323.

von Stengel S, Kemmler W, Engelke K, Kalender WA. Effect of wholebody vibration on neuromuscular performance and body composition for females 65 years and older: a randomized-controlled trial. Scand J Med Sci Sports 2012;22:119-127. 